\title{
UNA INCURSIÓN MÉTRICA EN LA POESÍA DE NICANOR PARRA
}

\author{
A PROSODY FORAY INTO \\ NICANOR PARRA'S POETRY
}

\author{
CARlos Mármol \\ Universidad de Sevilla
}

Resumen: El objeto de este artículo es hacer una incursión métrica en el código lírico sobre el que se sustenta la denominada antipoesía de Nicanor Parra a partir de la comparación crítica de dos de sus antipoemas con referentes procedentes de la tradición de la mejor poesía escrita en español del siglo xx (Machado y Borges). De dicho contraste se desprende que el discurso poético presente en la obra del poeta chileno cuestiona una serie de convenciones del discurso lírico tradicional con el afán de superarlas. Dicha renovación lírica, sin embargo, no se reduce a la mera oposición con respecto a la tradición, sino que busca reorientar la enunciación lírica hacia una sensibilidad más acorde con el hombre de nuestro tiempo.

Palabras clave: Nicanor Parra, poesía, antipoesía, tradición, prosaísmo, lírica.

Abstract: The purpose of this article is to make a foray into the lyrical metric code which the antipoetry of Nicanor Parra is based in though a review of two of its antipoems with references from the best poetry written in Spanish during XX Century (Machado and Borges). From this contrast it appears 
clearly that the poetic discourse in the work of Chilean poet challenges a number of conventions of traditional lyrical speech in an effort to overcome them. This lyrical renewal, however, is not based solely on opposition to tradition, but seeks to reorient the lyrical enunciation sensitivity much more in line with the man of our time.

Keywords: Nicanor Parra, poetry, anti-poetry, tradition, prosaism, lyric. 
El verdadero Cristo es lo que es en cambio yo qué soy: lo que no soy ${ }^{1}$

NicANor PARRA

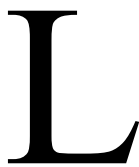

a obra del chileno Nicanor Parra ha sido definida por el crítico norteamericano Harold Bloom ${ }^{2}$ como un ejercicio «persuasivamente irreverente» sobre la función de la poesía en los tiempos contemporáneos. Si damos por válida dicha aseveración, lo cual supone no tanto aceptarla en su integridad, sino concederle al menos el crédito necesario para poder cuestionarnos el fondo a partir del cual nace su argumentación, convendría preguntarse exactamente sobre qué o quién proyecta Parra su famosa irreverencia. ¿Sobre la poesía tal y como la hemos entendido a lo largo de los siglos? ¿Sobre el lenguaje poético? ¿Sobre una determinada sensibilidad lírica?

Responder no es fácil. Una de las características de la producción poética del escritor chileno es su constante mutación. $\mathrm{Su}$ poesía es la protagonista pertinaz de un proceso de cambio continuo que, aunque anclado en la realidad, ha dado lugar a diversos experimentos y atrevimientos poéticos; en algunos casos

\footnotetext{
${ }^{1}$ PARra, Nicanor: Nuevos sermones y prédicas del Cristo de Elqui. Valparaíso: Ediciones Ganymedes, 1979. Obras completas \& algo + (1975-2006). Barcelona: Galaxia Gutenberg, 2011, p. 37.

2 Bloom, Harold: Prefacio a PARRA, Nicanor: Obras completas \& algo $+(1935-1972)$. Barcelona: Galaxia Gutenberg, 2006, p. 28.
} 
sorprendentes, en otros algo más discutibles si los contemplamos desde la perspectiva ortodoxa del ejercicio del verso. Con independencia de cuál sea la opinión al respecto, e incluso si ésta es negativa, existe un cierto consenso general sobre el impacto que en su día supuso la irrupción del singular discurso lírico de Parra. Según la mayor parte de la crítica, el poeta chileno alteró la poesía escrita en español en 1954, fecha de la publicación de Poemas y antipoemas, su segundo libro ${ }^{3}$, que instauró una manera de decir el verso que coloca al prosaísmo como eje central de una producción lírica que cuestiona la tradición heredada, pero también supera a las distintas corrientes de poesía coloquial que venían cultivándose en Hispanoamérica desde la época del Modernismo tardío - cuando el cisne ya no tenía cuello, por usar el famoso símil del mexicano Enrique González Martínez ${ }^{4}$ hasta nuestros días, todavía marcados por el acercamiento de la poesía a la sensibilidad del hombre moderno.

Parra expresa muy bien en su obra esta voluntad de su tiempo de desmitificar la enunciación poética a través de un registro que en ocasiones ha hecho dudar sobre la naturaleza del propio hecho lírico. En paralelo a la crisis de la poesía clásica, en apariencia alejada de las necesidades del hombre de nuestros días, el escritor chileno ha construido su propia tradición, aunque en vez de hacerlo mediante una oposición directa al canon lírico occidental, su poesía buscaría renovarlo a través de una profunda limpieza del andamiaje retórico y crítico surgido a su alrededor. $\mathrm{Su}$ intención última es devolver el lenguaje poético a su raíz esencial. «En la poesía se permite todo», ha defendido el poeta chileno, marcando distancias con quienes conciben la lírica exclusivamente como un conjunto de normas métricas y reglas fijadas a lo largo de la historia de la literatura.

Las apariencias, no obstante, dejan cabos sueltos. Para burlarse de cualquier tradición conviene antes conocerla en profundidad. Este rasgo es justo el que diferencia a Parra de otros muchos provocadores líricos: al dominar la tradición su ruptura no es completa ni frontal, sino irónica y lateral. Mucho más inteligente.

\footnotetext{
${ }^{3}$ PArra, Nicanor: Poemas y antipoemas. Santiago: Nascimiento, 1954.

${ }^{4}$ Escritor mexicano autor del poemario Los senderos ocultos. México: Porrúa Hermanos, 1911.
} 
Aunque el poeta opta por temas y motivos de clara índole prosaica, en buena parte de su producción poética compensa esta elección estética con una relativa estabilidad rítmica caracterizada por el uso del endecasílabo y otros versos de ritmo impar. La tendencia al versolibrismo y la presencia de lo prosaico son síntomas de la voluntad de arrancar de la poesía todo aquello que se ha convertido en convención o retórica muerta. Pero esto no implica necesariamente el destierro de algunas formas métricas consideradas útiles. Decir que la poesía de Parra está marcada por el coloquialismo, que opta por el habla común y que recuerda el afán contestatario de las vanguardias no es sino hacer un análisis epidérmico. Para comprender en su integridad la renovación poética del escritor chileno debemos profundizar en el punto de partida sobre el que trabaja el poeta, estudiar sus procedimientos líricos y evaluar el resultado final. Dichas fases están desarrolladas en la teoría del antipoema esbozada por Iván Carrasco ${ }^{5}$ hace ya un cuarto de siglo, cuyas líneas generales son una buena guía para el acercamiento a la lírica de la antipoesía.

\section{II}

Me parece que el éxito será completo Cuando logre inventar un ataúd de doble fondo Que permita al cadáver asomarse a otro mundo ${ }^{6}$

NicANOR PARRA

Iván Carrasco $^{7}$ parte de la idea de que la obra de Parra no es sólo coloquial, sino que intenta modificar la percepción misma de lo poético. A su juicio, la operativa lírica del poeta chileno persigue hacer una «reescritura» a conciencia del canon. No se trata, en su opinión, de la habitual diatriba entre el respeto o el cuestionamiento de determinadas normas métricas. Parra, según Carrasco, quiere escribir poesía desde cero. Y para conseguirlo

\footnotetext{
${ }^{5}$ CARrasco, Iván: Nicanor Parra: La escritura antipoética. Santiago de Chile: Editorial Universitaria, 1990.

${ }^{6}$ PARRA, Nicanor: Obras completas \& algo, cit.

${ }^{7}$ CARrasco, Iván: Nicanor Parra, cit.
} 
aplica sobre la tradición una metodología que se resume en tres pasos. El primero consiste en homologarse, por analogía, con el objeto que se va a cuestionar: el poema. La segunda fase invierte los valores estéticos aceptados, pero no de forma rotunda, sino ambigua; sin llegar a romper del todo con la tradición. La última etapa satiriza lo literario, deformándolo, lo que obliga al lector a poner en cuestión toda la convención lírica heredada, dejándolo sin los asideros aprendidos e invitándolo así a preguntarse en qué consiste en realidad la enunciación poética. No son fases mecánicas, sino aproximativas. En la extensísima obra de Parra los ejemplos son más intensos en unos casos y menos en otros. Lo que implica que no siempre podemos hablar de cortes radicales con el cordón umbilical de la tradición, sino más bien de quiebros.

El aspecto métrico, igual que otros elementos relacionados con la enunciación lírica, también participa de esta ceremonia de desmontaje de mitos literarios que, en el fondo, es la obra de Parra. ¿Qué tipo de verso elige el poeta chileno para cumplir su objetivo? ¿Verso libre o irregular? ¿Acaso no son lo mismo? Sobre esta cuestión existe un debate entre los expertos. Quilis identifica ambas categorías ${ }^{8}$. Domínguez Caparros cataloga el verso libre como una variante del verso irregular ${ }^{9}$. A juicio de Navarro Tomás, «los versos libres son versos que no obedecen ni a la igualdad de las sílabas ni a la uniformidad de las cláusulas ${ }^{10}$. Utrera Torremocha clasifica el verso libre dentro de las distintas formas irregulares: «Por versificación irregular se entiende siempre aquélla que no está regida por el principio de la igualdad en el número de sílabas métricas $\rangle^{11}$. En muchos poemas de Parra encontramos, a pesar de su registro prosaico, una regularidad métrica. También podríamos argumentar que en realidad se trata de un verso fluctuante, que, según Utrera Torremocha, es el verso cuya «irregularidad silábica se ajusta a una ametría limitada a unas medidas próximas, mientras que los versos libres no obedecen ni a igualdad de número ni a uniformidad de cláusulas»».

\footnotetext{
${ }^{8}$ Quilis, Antonio: Métrica Española. Barcelona: Ariel, 1984.

${ }^{9}$ Domínguez Caparrós, José: Métrica Española. Madrid: Síntesis, 1993, pp.53-59.

${ }^{10}$ Navarro Tomás, Tomás: Métrica española. Barcelona: Labor, 1991, p. 39

${ }^{11}$ Utrera Torremocha, María Victoria: Historia y teoría del verso libre. Sevilla: Padilla Libros Editores, 2001, pp.13-14.
} 
La situación, pues, induce al desconcierto si hemos aceptado sin más la opinión de la crítica que identifica la antipoesía con la ausencia de métrica. Tratar temas vulgares con un patrón métrico, por muy flexible que éste sea, quiere decir que el prosaísmo de Parra no llegaría en el fondo a despegarse del todo de la tradición métrica, aunque intente compensar dicha tendencia con elementos temáticos de orden común, cotidianos. ¿Por qué Parra no rechaza la regularidad rítmica del endecasílabo al hacer antipoesía? Para responder es preciso analizar antes cuál es la percepción del poeta sobre la naturaleza de esta forma versal ${ }^{12}$. A juicio de Niall Binns, «el uso del endecasílabo (en Parra) es más una parodia que una vuelta a la tradición literaria». Sin embargo, no es un hecho azaroso, sino fruto de una intención: «el endecasílabo es un medio para alcanzar una poesía realmente hablada», precisa.

Según las propias palabras del poeta chileno, «si el octosílabo de la poesía popular nació de los ritmos del habla popular del medievo, el endecasílabo representa el grupo fónico que correspondería al habla más sofisticada de la burguesía moderna». Binns nos dice que, según Parra, «la transformación entre estos dos ritmos se anuncia desde las primeras palabras de El Quijote, donde el octosílabo inicial, escrito con el idioma de Sancho, da lugar enseguida al endecasílabo, que nos traslada en el acto a la modernidad». Dicho en palabras del propio poeta: «si no uso el endecasílabo estoy renunciando poco menos que a la columna vertebral del lenguaje, del idioma español».

Lejos de indicar un amor secreto por las reglas líricas tradicionales, la frecuente aparición del endecasílabo respondería más bien al sentido común. La antipoesía no quiere romper necesariamente con la métrica: la utiliza en función de su idoneidad. Prescindirá de dicha obligación normativa si ésta choca con su intención comunicativa, pero no rechazará su presencia cuando contribuya al objeto del poema. A medida que la obra de Parra avanza, el alejamiento con respecto a la métrica clásica se hará más intenso, pero en los primeros poemarios todavía vemos cómo coexiste el verso libre con una hábil selección de recursos

${ }^{12}$ Tomamos el análisis de dicha teoría de BINNS, Niall: Introducción a PARRA, Nicanor: Obras Completas \& algo + (1935-1972), cit., p. 52-53. 
métricos ordinarios. Los antipoemas, en efecto, no obvian el ritmo. Entre otras cuestiones porque la ametría siempre tiene su razón de ser, como explicó en su momento Esteban Torre, «en los esquemas métricos, de los que representa, según el caso, una confirmación, un desvío o una expectativa frustrada». Federico $\mathrm{Schopf}^{13}$ arroja algo más de luz sobre las razones por las que $\mathrm{Pa}-$ rra trabaja tanto con el endecasílabo al estimar que este tipo de verso no limita su libertad poética, sino que es una formal versal natural y muy próxima al famoso «fantasma de la tribu» ${ }^{14}$ que el poeta desea resucitar:

Los antipoemas [...] surgen de una ruptura con los sistemas o códigos de la poesía anterior (incluido el vertiginoso movimiento de las vanguardias). Pero no se constituyen a partir de una oposición excluyente, rasgo a rasgo, en relación con las distintas variedades de poemas anteriores. Incluso Parra ha llegado a descubrir, con el paso del tiempo, una lista de precursores antipoéticos [...] Los antipoemas como conjunto se oponen a los conjuntos anteriores de poemas, aunque tengan en común con ellos algunos de sus elementos, pero recontextualizados, esto es coexistiendo con otros componentes, reorientados en sus significaciones y referencias, que se iluminan aún más sobre el trasfondo familiar de sus significaciones normales.

Dos ejemplos expresos de esta reordenación de la tradición lírica los encontramos en los poemas Autorretrato ${ }^{15}$ y Quédate con tu Borges ${ }^{16}$. El primero dinamita el género del retrato que un poeta hace sobre sí mismo. Una tradición en la historia de la literatura que podríamos ejemplificar, desde una óptica cercana, en el caso del célebre Retrato ${ }^{17}$ de Antonio Machado.

El poema machadiano está escrito en serventesios ${ }^{18}$, una forma métrica vinculada al Modernismo de primera hora. El retrato

${ }^{13}$ Schopf, Federico: Genealogía y actualidad de la antipoesía: un balance provisorio. Prólogo a PARRA, Nicanor: Obras Completas \& algo + (1935-1972), cit.

${ }^{14}$ Leónidas Morales, T: Conversaciones con Nicanor Parra. Santiago de Chile: Editorial Universitaria, 1990.

${ }^{15}$ PARRA, Nicanor: Obras Completas \& algo, cit.

${ }^{16}$ Iván Carrasco explica en su estudio sobre la obra lírica de Parra que dicho poema no está incluido en ningún poemario. El poeta, según este relato, se lo regaló personalmente al crítico «en un gesto de amistad».

${ }^{17}$ Machado, Antonio: Campos de Castilla. Madrid: Renacimiento, 1912.

${ }^{18}$ El serventesio es el nombre con el que se designa a veces a la redondilla o al cuarteto de rimas cruzadas, según la denominación de NAvArro Tomás, Tomás: Métrica española, cit., p. 539. 
que el poeta hace de sí mismo se caracteriza aquí por el distanciamiento, perceptible desde el mismo título. Evidentemente, es un autorretrato, pero Machado evita usar este término y lo reemplaza por otro cuya connotación es bastante más objetiva: el retrato. Al tratarse de una descripción aparecen elementos íntimos del poeta, si bien contemplados con bastante desapego. Las alusiones personales son genéricas, no concretas. El individualismo del poeta además está contenido: no entra en detalles ciertos. El poema recurre a tópicos literarios bien anclados en la tradición occidental. Usa un lenguaje culto y elevado que se presenta en sociedad bajo la forma del soliloquio.

Parra, en cambio, invierte este modelo lírico tan definido y opta por otro donde el prosaísmo atenúa el tono elevado del poema machadiano.

\section{Autorretrato}

Considerad, muchachos,

Este gabán de fraile mendicante:

Soy profesor de un liceo obscuro,

He perdido la voz haciendo clases.

(Después de todo o nada

Hago cuarenta horas semanales).

¿Qué les dice mi cara abofeteada?

¿Verdad que inspira lástima mirarme!

qué les sugieren estos zapatos de cura

Que envejecieron sin arte ni parte.

En materia de ojos, a tres metros

No reconozco ni a mi propia madre.

¿Qué me sucede? ¡Nada!

Me los he arruinado haciendo clases:

La mala luz, el sol,

La venenosa luna miserable.

¡Y todo para qué!

Para ganar un pan imperdonable

Duro como la cara del burgués

Y con olor y con sabor a sangre.

¡Para qué hemos nacido como hombres

Si nos dan una muerte de animales! 
Por el exceso de trabajo, a veces

Veo formas extrañas en el aire,

Oigo carreras locas,

Risas, conversaciones criminales.

Observad estas manos

Y estas mejillas blancas de cadáver,

Estos escasos pelos que me quedan.

¡Estas negras arrugas infernales!

Sin embargo yo fui tal como ustedes, joven lleno de bellos ideales,

Soñé fundiendo el cobre

Y limando las caras del diamante:

Aquí me tienen hoy

Detrás de este mesón inconfortable

Embrutecido por el sonsonete

De las quinientas horas semanales
11

$11 \mathrm{~A}$

7

$11 \mathrm{~A}$

7

$11 \mathrm{~A}$

11

$11 \mathrm{~A}$

11

$11 \mathrm{~A}$

7

$11 \mathrm{~A}$

7

$11 \mathrm{~A}$

11

$11 \mathrm{~A}$

La escansión de los versos nos descubre que el poema sigue un patrón rítmico endecasilábico: el endecasílabo se combina con heptasílabos y un solitario verso de catorce sílabas. Se trata de un conjunto de versos irregulares que componen una silva arromanzada: un poema de ritmo impar con rima en romance en los pares, según la definición de Isabel Paraíso. Se trata de una forma métrica frecuente en la poesía libre del siglo Xx. El cómputo de sílabas nos indica también que estamos ante una pauta métrica. Dos elementos más inciden en esta misma dirección: la escasa utilización de encabalgamientos abruptos, utilizados para desmantelar el verso tradicional; y la repetición de los dos últimos grupos de versos, donde se percibe un modelo determinado de rima y medida: 11/11/7/11/7/11/11/11. Esta elección indica que Parra tiene una clara conciencia constructiva. La regularidad se percibe asimismo en la distribución de la rima y en el ritmo impar. El poeta chileno no parece querer desdibujar por completo el ritmo de poema, aunque sí el estilo, al situar el prosaísmo como elemento de referencia.

El poema de Parra se escapa de la tradición del género (el texto de Machado sería en cambio una reformulación modernista del canon) pero utilizando la métrica para resaltar el contraste existente entre la forma y el fondo, que es una manera de invertir 
la convención lírica clásica. Parra no idealiza su imagen (se retrata como profesor, no como poeta) y se sumerge en una realidad vulgar. Su ideal no es la belleza, sino el prosaísmo. No se trata ya de un retrato literario, sino tomado del natural: sin referencias cultas (al contrario de Machado) y sin un lenguaje retórico. La fórmula elegida rompe cualquier tipo de decoro literario. Las descripciones no tienen piedad porque el poeta tampoco la tiene consigo mismo. Su discurso incluye exageraciones populares y, en lugar de un soliloquio, como en el caso de Machado, el texto se presenta bajo la forma de un teórico diálogo entre el profesor y sus alumnos. No hay espacio para la nostalgia. Tan sólo en la última estrofa se evoca el pretérito del profesor decrépito, que sigue dando clases en «un liceo obscuro», «sin voz», «con la cara abofeteada» y «zapatos de cura», «embrutecido por el sonsonete/ de las quinientas horas semanales».

En el caso de Quédate con tu Borges estamos ante un texto breve: apenas siete versos. Está construido a partir de una línea de uno de los dos poemas ingleses escritos por Jorge Luis Borges en 1934. En estos poemas, compuestos originalmente en lengua inglesa, Borges ensaya una lírica próxima a Walt Whitman y a T.S. Eliot. El verso de Borges sobre el que Parra monta su poema es el siguiente:

I offer you the memory of yellow rose seen at sunset, years before you were born.

El poema comienza con una perífrasis casi literal del verso borgiano que se extiende a lo largo de tres versos más, distintos y construidos sin puntuación. Parra inicia su poema in media res, dando por hecho, de entrada, que el lector ya conoce el poema de Borges. Parte pues de la literatura.

$\begin{array}{ll}\text { Quédate con tu Borges } & \\ & \\ \text { él te ofrece el recuerdo de un rosa amarilla } & 14 \\ \text { vista al anochecer } & 7 \\ \text { años antes que tú nacieras } & 9 \\ \text { interesante puchas qué interesante } & 12(7-5) \\ \text { en cambio yo no te prometo nada } & 11 \\ \text { ni dinero ni sexo ni poesía } & 11 \\ \text { un yogurt es lo + que podría ofrecerte } & 14\end{array}$


El poema no responde a ningún modelo cerrado de estrofa. Los versos son irregulares pero de ritmo endecasilábico. Según explica Carrasco ${ }^{19}$, Parra reproduce el verso del poema borgiano respetando su métrica, si bien distribuida ahora en tres líneas diferentes. El efecto rítmico se conserva en esta primera parte del poema, pero muta a medida que avanza el texto. El poema está concebido a partir del contraste entre estos tres primeros versos y los tres últimos, que son dos endecasílabos más un alejandrino. El texto empieza con un alejandrino y termina con otro, lo que alimenta la idea de una estructura circular. Los versos, sin embargo, dicen cosas radicalmente distintas. El primero emula el estilo poético de Borges, mientras que el segundo es de una vulgaridad notable. Puro Parra. Lo cual nos lleva a la tesis de Esteban Torre ${ }^{20}$ : «La poesía no tiene por qué manifestarse, necesaria y exclusivamente, a través del verso. Puede haber poesía sin versos. Y puede haber versos carentes de poesía». ¿El último alejandrino es poesía? Más bien sería su reverso: antipoesía. Construido con las mismas sílabas e idéntico ritmo que un alejandrino clásico, su sentido se aleja del referente tradicional. Todo lo que promete el primer alejandrino lo desmonta el segundo. Uno es la cara; el otro la cruz.

Esta inversión de valores se extiende al resto del poema. A juicio de Carrasco los tres primeros versos forman parte del proceso de homologación que define la fase inicial de la antipoesía. Parra replica a Borges (a quien no se cita en el primer verso, pero sí en el título del poema), se separa después de su sensibilidad y cuestiona por último su retórica con un enfoque terrestre. La métrica, sin embargo, permanece.

El cambio de tono se percibe muy bien en el cuarto verso, donde el estilo borgiano se quiebra e irrumpe el parriano. Estaríamos aquí en la segunda etapa del método antipoético: la separación de la convención lírica. El escritor chileno ironiza finalmente con la dicción de Borges - «qué interesante puchas qué interesante»- y abre el portillo al habla coloquial, alejándose rápidamente de la enunciación lírica inicial. Llegaríamos de esta

${ }^{19}$ CARrasco, Iván: Nicanor Parra, cit., pp. 38-42.

${ }^{20}$ Torre, Esteban; VázQuez Medel, Manuel Ángel: Fundamentos de poética española. Sevilla: Alfar, 1986. p. 15. 
manera a la última etapa de la antipoesía: la deformación poética de la propia poesía. Parra hace todo este viaje sin perder nunca la forma métrica del alejandrino, que igual le sirve para ofrecer «el recuerdo de una rosa amarilla/vista al anochecer/años antes que tu nacieras» que para compensar a la amada, ante la falta de algo mejor, con un miserable yogurt. El poeta, en el texto de Borges, ofrece lo mejor de sí mismo: su propia persona. Parra, por el contrario, considera ofrenda de amor un referente prosaico. La conexión espiritual que buscaba Borges queda reducida en el antipoema a una mera vinculación material, una vulgaridad objetiva que, sin embargo, es presentada ante el lector como un regalo. Parece una ironía, pero si tenemos en cuenta el contexto literario desde el que Parra escribe -el desgaste de las convenciones líricas tradicionales- a veces la única forma de ser poético consiste en ser vulgar.

\section{Bibliografía utilizada}

BINNS, Niall: Introducción a PARRA, Nicanor: Obras Completas \& algo + (1935-1972). Barcelona: Galaxia Gutenberg, 2006.

BORGES, Jorge Luis: «Two English Poems» en El otro, el mismo. Buenos Aires: Emecé, 1969.

CARRASCO, Iván: Nicanor Parra, la escritura antipoética. Santiago de Chile: Editorial Universitaria, 1990.

DE COSTA, René: «Para una poética de la (anti)poesía», en PARRA, Nicanor: Poemas y antipoemas. Madrid: Cátedra, 1988.

DOMÍNGUEZ CAPARRÓS: Métrica Española. Madrid: Síntesis, 1993.

LEÓNIDAS MORALES, T.: Conversaciones con Nicanor Parra. Santiago de Chile: Editorial Universitaria, 1990.

MACHADO, Antonio: Campos de Castilla. Madrid: Renacimiento, 1912.

NAVARRO TOMÁS, Tomás: Métrica española. Barcelona: Labor, 1991.

PARRA, Nicanor: Poemas y antipoemas. Santiago: Nascimiento, 1954.

-Nuevos sermones y prédicas del Cristo de Elqui. Valparaíso: Ediciones Ganymedes, 1979.

-Obras Completas \& algo + (1935-1972). Barcelona: Galaxia Gutenberg, 2006.

-Obras Completas \& algo + (1975-2006). Barcelona: Galaxia Gutenberg, 2011.

QUILIS, Antonio: Métrica Española. Barcelona: Ariel, 1984.

SCHOPF, Federico: Genealogía y actualidad de la antipoesía: un balance provisorio. Prólogo a PARRA, Nicanor: Obras Completas \& algo + (1935-1972). Barcelona: Galaxia Gutenberg, 2006. 
TORRE, Esteban: El ritmo del verso. Murcia: Universidad de Murcia, 1999. TORRE, Esteban y VÁZQUEZ MEDEL, Manuel Ángel: Fundamentos de Poética Española. Sevilla: Alfar, 1986.

UTRERA TORREMOCHA, María Victoria: Historia y teoría del verso libre. Sevilla: Padilla Libros Editores, 2001. 